Journal of

\title{
Differential responses of shrubs and herbs present at the Upper Minjiang River basin (Tibetan Plateau) to several soil variables
}

\author{
T. $\mathrm{Lu}^{\mathrm{a}, \mathrm{b}}$, K.M. Ma ${ }^{\mathrm{a}, *}$, W.H. Zhang ${ }^{\mathrm{c}}$, B.J. Fu ${ }^{\mathrm{a}}$ \\ ${ }^{a}$ State Key Lab of Systems Ecology, Research Centre for Eco-Environmental Sciences, \\ Chinese Academy of Sciences, Beijing 100085, China \\ ${ }^{\mathrm{b}}$ Graduate University of the Chinese Academy of Sciences, Beijing 100049, China \\ ${ }^{\mathrm{c}}$ Northwest Sci-tech University of Agriculture and Forestry, Yangling 712100, China
}

Received 29 January 2005; received in revised form 11 January 2006; accepted 9 March 2006

Available online 24 April 2006

\begin{abstract}
Vertical structure in plant communities is well recognized, but questions remain about the response of different stratal layers in a plant community to resource use. This study provides a quantitative approach to compare the relationships of nine edaphic factors and species distributions in shrub and herb layers, respectively, in an arid valley of the upper Minjiang River, Sichuan Province, China. Classification (TWINSPAN) determined three groups of shrubs and four groups of herbs. Ordination (both DCA and DCCA) found a correlation among species and edaphic variables. Borcard's method [Borcard, D., Legendre, P., Drapeau, P., 1992. Partialling out the spatial component of ecological variation. Ecology 73, 1045-1055.] was employed to partition the variation of species abundance data into independent components: pure spatial, pure environmental, spatial component of environmental influence, and undetermined. Based on those four components, a quantitative comparison of ecological variation between shrubs and herbs further eluidated their different response to the environment. Although soil moisture (SM) content, $\mathrm{pH}$, soil organic matter (OC) and available potassium (AK) were the most important factors to both, the explained ecological variation of herbs was lower than that of shrubs. Understanding differences between stratal layers in resource use can shed light on plant-environment relationships.
\end{abstract}

(C) 2006 Published by Elsevier Ltd.

Keywords: Arid vegetation; Classification; Herb; Ordination; Shrub; Species-environment relationships

\footnotetext{
${ }^{*}$ Corresponding author. Tel./fax: +861062849104 .

E-mail address: mkm@rcees.ac.cn (K.M. Ma).
} 


\section{Introduction}

The relationship between vegetation and environment has been a subject of many ecological studies in history (ter Braak, 1987; El-Ghareeb and Shabana, 1990; Dargie and El-Demerdash, 1991; McDonald et al., 1996; Abbadi and El-Sheikh, 2002; Vogiatzakis et al., 2003; Jafari et al., 2004), and understanding the different ecological processes among stratal layers has long been recognized as a key issue in plant community ecology. Most of these studies have either focused on facilitative and competitive interactions between woody and herbaceous plants (Pugnaire et al., 1996; Pugnaire and Lazaro, 2000; Holzapfel and Mahall, 1999; Maestre et al., 2003), or on feedbacks in the dynamics of plant communities. Such feedbacks include the ability of plant species to improve their environments by enhancing nutrient availability or nutrient capture (Hobbie, 1992; Wilson and Agnew, 1992), and differences between species in soil water use efficiency (Ehleringer et al., 1991; Lin et al., 1996; Schwinning et al., 2005a). However, it is possible that woody and herbaceous plants within the same community respond to environment differently, and thus the different stratal layers in vegetation represent niche partitioning.

Our study was carried out along the mountainous arid upper Minjiang River valley, an area suffering from land degradation but also identified for potential ecosystem restoration. Vegetation damage along the upper Minjiang River has taken place for at least a thousand years (Editorial Board of Sichuan Vegetation, 1980; Zhang, 1992), and serious soil erosion has occurred, degrading soil water and nutrient conditions (He et al., 1993; Lei and Huang, 1993; Ma et al., 2004). In this harsh habitat, the apparent structural simplicity of plant communities and the shrub/herb association provides an ideal model system to study layer response. Furthermore, since this habitat requires restoration, knowledge of differential layer response could help to identify strategies that would improve restoration success.

Among different environmental factors, soil is normally of great importance in plant growth, and is a function of climate, organisms, topography, parent material and time (Jafari et al., 2004). The relationships between vegetation and soil characteristics can be an important tool to assess sites, and the presence/absence of species can be used as bioindicators of soil conditions (Turner and Kelly, 1981; Wang, 1995). Therefore, soil was selected as the most important environmental factor in our study.

Our study focused on two questions: (1) how do shrub and herb layers respond to a same environment; and (2) to what extent is the total ecological variation explainable by each layer.

\section{Methods}

\subsection{Study area}

The Minjiang River is a first-order branch of the Yangtze River, which is about $735 \mathrm{~km}$ in length and has an altitude range of $3560 \mathrm{~m}$. The upper Minjiang River Basin $\left(102^{\circ} 41^{\prime}-103^{\circ} 58^{\prime} \mathrm{E} ; 30^{\circ} 44^{\prime}-32^{\circ} 24^{\prime} \mathrm{N}\right)$ is a $337 \mathrm{~km}$ section between the headwaters and Dujiangyan City. The Basin is found in the northwestern corner of Sichuan Province, in a transition zone bounded on the west by the Tibetan Plateau and bounded on the east by the Sichuan Basin. 
In the upper Minjiang River basin, maximum elevation is $>3600 \mathrm{~m}$ in the headwaters and the minimum elevation is $<900 \mathrm{~m}$ in Dujiangyan City. The mountainous topography has a large degree of vertical variation in precipitation and air temperature. The arid valley under study is located between 1300 and $2200 \mathrm{~m}$ in a semi-arid climate. Mean annual precipitation is near $500 \mathrm{~mm}$, mean annual potential evapo-transpiration is about $1332 \mathrm{~mm}$, and mean annual temperature is about $11.2^{\circ} \mathrm{C}$.

Soils are classified as Calcic cambisols (FAO-UNESCO, 1988). Vegetation here is dominated by arid shrubs, such as Sophora viciifolia, Indigofera bungeana, and Bauhinia faberi var. microphylla, and sparse grasses, such as Ajania breviloba, Sedum wenchuanense and Heteropogon contortus.

\subsection{Data collection}

Field experiments were carried out at three sites (Fig. 1) that reflect different vegetation zones, located in the arid valley during August 2001. Shidaguan, on the upper reaches of the core area, was dominated by short dry grasses and dwarf dry shrubs, on both north- and south-facing slopes. Within the central part, Feihongguan, vegetation consisted only of sparse dwarf dry shrubs on north facing slopes and sparse grasses on south facing slopes. Within the lower portion, Wenchuan, some small trees occupied north-facing slopes, but only sparse shrubs were present on south-facing slopes.

At each site, two transects were placed on opposite (i.e. south and north facing) slopes, oriented to make a 'V' shape. Sample plots were set up along transects with points at about $20 \mathrm{~m}$ intervals. Sample plots were $25 \mathrm{~m}^{2}(5 \times 5 \mathrm{~m})$ homogenous plots. In these plots, all shrub species were identified and measured for layer coverage, total height and frequency.

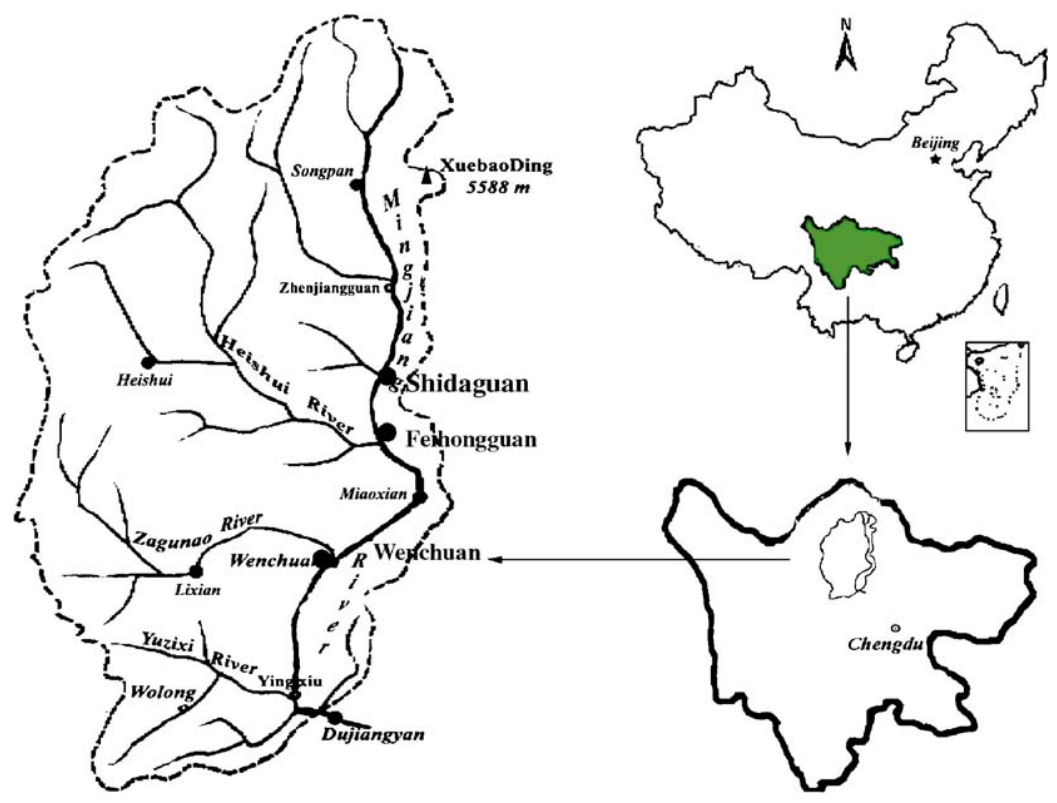

Fig. 1. Location of the sample sites along the Upper Minjiang River, China. 
Within each sample plot, three quadrats $(1 \times 1 \mathrm{~m})$ on the diagonal line were chosen, where herb species were identified and measured for layer coverage and height. Normally, three sample plots were set up in each vegetation zone, but occasionally only one or two plots were feasible, particularly when the vegetation zone was narrowly distributed on the slope. More than three plots were sampled if the vegetation area was large enough. A total of 53 plots were sampled (Table 1, Fig. 2).

Knowing that soil moisture (SM) varies over time due to fluctuations in rainfall and plant water requirements in the summer season and the importance of keeping the sampling conditions similar, SM was collected on sunny days within a 2-week period. Within each sample plot, moisture of the surface soil $(0-15 \mathrm{~cm})$ was determined at nine points using a portable Time Domain Reflectometry (TDR). Also, five soil samples $(0-20 \mathrm{~cm})$ were collected using cores $(5 \mathrm{~cm}$ diameter $)$ from five random soil profiles, air-dried, thoroughly mixed, and passed through a $2 \mathrm{~mm}$ sieve to remove gravel and debris. Soil finer than $2 \mathrm{~mm}$ were kept for further chemical analyses. The semimicroKjeldahl method was used to determine the total soil nitrogen (TN). Total phosphorus (TP) was determined colorimetrically after wet digestion with $\mathrm{H}_{2} \mathrm{SO}_{4}$ plus $\mathrm{HClO}_{4}$ (Parkinson and Allen, 1975). Available nitrogen (AN) was determined by the Cornfield method (alkaline hydrolysable nitrogen). Available potassium (AK) and available phosphorus (AP) were extracted with $3 \%\left(\mathrm{NH}_{4}\right)_{2} \mathrm{CO}_{3}$ solution. After filtering, the solution was measured by icp-aes (Editorial Committee, 1996). Soil organic matter (OC) was determined by the $\mathrm{K}_{2} \mathrm{Cr}_{2} \mathrm{O}_{7}$ titration method after digestion (Nelson and Sommers, 1975). Total potassium (TK) was determined by atomic absorption spectrometer (Editorial Committee, 1996). Soil pH was determined in 1:2.5 soil-water slurry. To improve the precision of the results, three replicates were analysed and averaged for each of the soil nutrient analyses.

Table 1

Mean and standard deviation $( \pm)$ of environmental variables for the plots associated with each of the three sites

\begin{tabular}{|c|c|c|c|c|c|c|}
\hline \multirow{2}{*}{$\begin{array}{l}\text { Site } \\
\text { Transect no. }\end{array}$} & \multicolumn{2}{|l|}{ Shidaguan } & \multicolumn{2}{|c|}{ Feihongguan } & \multicolumn{2}{|l|}{ Wenchuan } \\
\hline & $\mathrm{T}_{1}$ & $\mathrm{~T}_{2}$ & $\mathrm{~T}_{3}$ & $\mathrm{~T}_{4}$ & $\mathrm{~T}_{5}$ & $\mathrm{~T}_{6}$ \\
\hline Plot number & $1-16$ & $17-27$ & $28-32$ & $33-40$ & $41-47$ & $48-53$ \\
\hline Altitude (m) & $1963 \pm 137$ & $2036 \pm 53$ & $1778 \pm 102$ & $1931 \pm 36$ & $1438 \pm 54$ & $1428 \pm 37$ \\
\hline Aspect (deg) & $306 \pm 9$ & $218 \pm 13$ & $189 \pm 11$ & $341 \pm 14$ & $193 \pm 14$ & $317 \pm 10$ \\
\hline Slope (deg) & $32 \pm 2$ & $33 \pm 3$ & $38 \pm 3$ & $37 \pm 1$ & $33 \pm 3$ & $33 \pm 5$ \\
\hline Shrub layer coverage $(\%)$ & $67 \pm 5$ & $49 \pm 18$ & $31 \pm 4$ & $42 \pm 19$ & $52 \pm 9$ & $72 \pm 14$ \\
\hline Herb layer coverage $(\%)$ & $75 \pm 16$ & $46 \pm 13$ & $17 \pm 2$ & $36 \pm 10$ & $48 \pm 4$ & $68 \pm 11$ \\
\hline Soil moisture content $(\%)$ & $13.5 \pm 2.4$ & $12.7 \pm 2.9$ & $6.9 \pm 1.0$ & $8.9 \pm 1.3$ & $11.4 \pm 1.2$ & $14.1 \pm 1.5$ \\
\hline $\mathrm{pH}$ & $7.2 \pm 0.3$ & $7.3 \pm 0.5$ & $8.7 \pm 0.4$ & $7.9 \pm 0.3$ & $7.3 \pm 0.2$ & $7.4 \pm 0.2$ \\
\hline Soil organic matter $(\%)$ & $13.7 \pm 2.9$ & $8.8 \pm 2.5$ & $5.5 \pm 1.7$ & $7.6 \pm 1.6$ & $9.0 \pm 0.6$ & $10.5 \pm 3.4$ \\
\hline Total nitrogen $(\%)$ & $0.49 \pm 0.14$ & $0.43 \pm 0.13$ & $0.30 \pm 0.07$ & $0.38 \pm 0.15$ & $0.41 \pm 0.06$ & $0.49 \pm 0.14$ \\
\hline Available nitrogen $(\mathrm{mg} / \mathrm{kg})$ & $289 \pm 74$ & $247 \pm 82$ & $157 \pm 31$ & $187 \pm 22$ & $206 \pm 39$ & $278 \pm 64$ \\
\hline Total potassium (\%) & $2.60 \pm 0.22$ & $3.05 \pm 0.24$ & $1.94 \pm 0.55$ & $2.18 \pm 0.44$ & $2.85 \pm 0.44$ & $3.02 \pm 0.32$ \\
\hline Available potassium $(\mathrm{mg} / \mathrm{kg})$ & $181 \pm 32$ & $135 \pm 33$ & $110 \pm 20$ & $127 \pm 20$ & $134 \pm 26$ & $188 \pm 32$ \\
\hline Total phosphorus (\%) & $0.07 \pm 0.01$ & $0.05 \pm 0.01$ & $0.05 \pm 0.01$ & $0.12 \pm 0.02$ & $0.07 \pm 0.02$ & $0.07 \pm 0.01$ \\
\hline Available phosphorus (mg/kg) & $4.09 \pm 1.38$ & $5.28 \pm 3.19$ & $7.07 \pm 1.85$ & $5.06 \pm 1.68$ & $3.10 \pm 0.89$ & $2.54 \pm 1.45$ \\
\hline
\end{tabular}




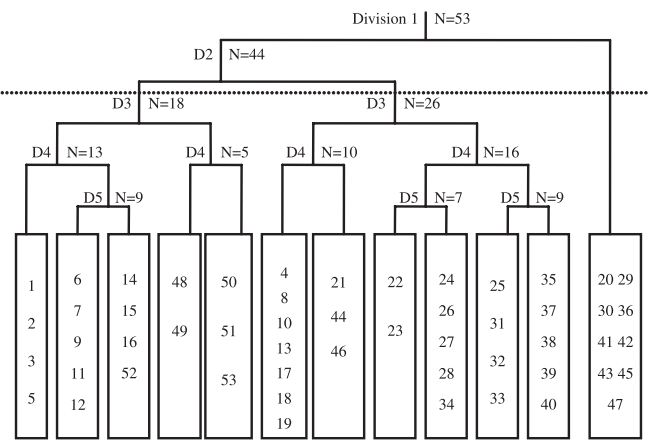

Shrubs

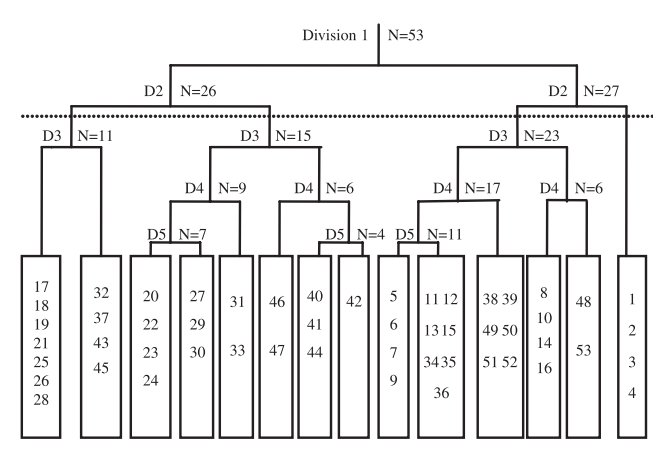

Herbs

Fig. 2. Dendrogram of the TWINSPAN classification of 53 plots. Note: Dx indicates the number of division; Nx indicates the number of plots.

\subsection{Data analysis methods}

In order to reveal similarities and differences between shrubs and herbs, and to obtain an effective analysis of the species and related soil factors, both classification and ordination techniques were employed in shrubs and herbs, respectively. Multivariate analyses were perfomed on two floristic data matrices; 53 samples and 38 species $(53 \times 38)$ in shrubs, and 53 samples and 41 species $(53 \times 41)$ in herbs. All species whose importance value was less than $1 \%$ were eliminated. An environmental data matrix of nine soil factors $(53 \times 9)$ was also made.

To simplify the continuum of species composition present in the study area and to aid our understanding of species-environment relationships, sample plots with generally similar species were classified into a few groups by two-way indicator species analysis (TWINSPAN) in both shrub and herb layers. TWINSPAN analysis is a numerical method for classification of vegetation samples into similar groups (Hill, 1979; Kent and Coker, 1992; Johnson, 1995; Oksanen and Minchin, 1997), which uses a divisive method of clustering (Gauch and Whittaker, 1981). The method is hierarchical, producing a dichotomized dendrogram of classes that can be considered at various levels of aggregation. Thus, by using TWINSPAN, we can recognize homogenous groups both in shrub and herb layers.

Relationships between species and soil factors were also studied using Detrended Canonical Correspondence Analysis (DCCA), as suggested by ter Braak and Prentice (1988). DCCA is a direct gradient analysis technique in which the axes of a vegetative ordination are restricted to linear groupings of environmental variables (Palmer, 1993). DCCA has some advantages over other ordinations in that it makes the interpretation of the axes easier, and has no marked horseshoe effect (ter Braak, 1986). In DCCA analysis however, meaningful environmental variables have been identified and measured. Thus, some other important factors may be lost. Therefore, in our study, results obtained from DCCA were compared with results from detrended correspondence analysis (DCA) to see if soil factors selected in our study contributed strongly to species variation. DCA is an indirect ordination technique, which ordinates the floristic data independently from environmental data (Kent and Coker, 1992). 
The spatial structure of a plant community observed at any point in time is the product of many processes in its past. The processes that are most important for shaping community structure are likely to leave observable imprints in spatial community structure (Schenk et al., 2003). To more clearly identify differences of species-environment relationships in shrubs and herbs, a subsequent comparison was made following Borcard et al.'s (1992) method. Before analysis, we oriented every sample plot with longitude, latitude and elevation, thus making a matrix of geographical coordinates of each plot. Using DCCA analysis, with the spatial matrix as covariable data, we partitioned the variation of species abundance data into independent components: pure spatial, pure environmental, spatial component of environmental influence, and undetermined, respectively. A comparison of ecological variation between shrubs and herbs was made based on those four components.

The TWINSPAN analysis was performed using the default settings of the computer program TWINSPAN (Hill, 1979). Both the DCA and the DCCA analysis were performed with the software package CANOCO 4.0 for Windows (ter Braak and Smilauer, 1998), with equal weight given to all variables and 26 segments used in detrending. No sample plots were omitted from the analysis as outlier observations. Monte Carlo permutation tests (99 permutations) were used to assess the significance of the DCCA ordination axes.

\section{Results}

\subsection{Vegetation classification}

TWINSPAN was performed on the 53 plots both in shrubs and herbs, and the stopping point of the cluster formation was set at the second level based on experience, which could produce up to three clusters in the shrub layer and four in the herb layer, respectively.

The shrubs were clustered into three groups as follows:

Group 1: This group of nine plots $(20,29,30,36,41,42,43,45,47)$ was mainly located on sunny slopes along transect $\mathrm{T}_{3}$ and $\mathrm{T}_{5}$, and was mostly dominated by Sophora viciifolia and Indigofera bungeana. Soils had high calcareous levels, and vegetation coverage was typically less than $40 \%$.

Group 2: Bauhinia faberi var. microphylla, Lespedeza floribunda and Sageretia pycnophylla were the characteristic species of Group 2, comprising 26 plots (4, 8, 10, 13, $17,18,19,21,22,23,24,25,26,27,28,31,32,33,34,35,37,38,39,40,44,46)$ mainly along transects $\mathrm{T}_{2}$ and $\mathrm{T}_{4}$. Most of the plots were on semi-sunny or -shady slopes.

Group 3: This group includes 18 plots $(1,2,3,5,6,7,9,11,12,14,15,16,48,49,50,51$, $52,53)$ distributed along transects $T_{1}$ and $T_{6}$. Indicator species for this group were Caryopteris terniflora and Leptodermis purdomi. Vegetation coverage was typically greater than $65 \%$.

Herbs were clustered into four groups as follows:

Group A: Pteris inaequalis was the indicator species for Group A, where vegetation had the highest coverage. This group includes four plots $(1,2,3,4)$ located only on the upper slopes along $\mathrm{T}_{1}$.

Group B: This group was prevalent on middle or lower slopes along almost all shady transects, and it included 23 plots $(5,6,7,8,9,10,11,12,13,14,15,16,34,35,36,38,39$, 48, 49, 50, 51, 52, 53). Onosma farrerii, Artemisia igniaria and Artemisia sylvatica dominated this group. 
Group C: In this group, nine plots $(20,22,23,24,27,29,30,31,33)$ were ubiquitous along transect $\mathrm{T}_{3}$, mostly located on sunny slopes where habitats were so arid that only a few species could survive. Heteropogon contortus and Ajania breviloba dominanted Group C, with Carex lanceolata as a co-dominant. The other six plots $(40,41,42,44,46,47)$ were distributed along $\mathrm{T}_{5}$. Sedum wenchuanense and Tragus berteronianus were similarly dominant with a co-dominant Rorippa montana.

Group D: This group included 11 plots $(17,18,19,21,25,26,28,32,37,43,45)$ had some similarities with Group C, and was mainly found on upper slopes along sunny transects. There were no obvious dominants. Setaria glauca, Capillipedium parviflorum, Carex crebra and Thalictrum thunbergii were similarly abundant.

To examine if resulting groups were significantly different, soil characteristics of each of the three vegetation groups in shrubs and four groups in herbs were summarized (Table 2). Of all measured soil parameters, SM, pH, AN, and TP showed highly significant differences among groups, meaning that both the shrub and herb TWINSPAN groups had significant soil differences.

\subsection{Vegetation ordination}

Eigenvalues in an ordination analysis represent the relative contribution of each axis to the explanation of the total variation in the data (Vogiatzakis et al., 2003). In this study, the eigenvalues in DCCA do not differ greatly from those derived from DCA (Table 3). The DCCA eigenvalues of the first two ordination axes explained $18.7 \%$ of the variance in the species data in shrubs and $15.9 \%$ in herbs. Moreover, a Monte Carlo test confirmed the statistical significance of these two axes $(p=0.01)$, both in the shrub layer and in the herb layer.

\subsubsection{Plots ordination}

TWINSPAN groups were superimposed onto the DCCA ordination (Fig. 3), with arrows indicating the edaphic variables. The groups derived from TWINSPAN were corroborated by DCCA, especially in shrubs, although there was some degree of overlapping in the ordination space among groups. These overlapped plots were close in proximity on the DCCA axis, but separated in the TWINSPAN divisions. Here, DCCA bi-plots were helpful for regrouping these sites without enforcing hard decision rules.

In shrubs, the first DCCA axis was mainly correlated to SM $(r=0.657)$ and percentage of pH $(r=-0.615)$, while $\mathrm{OC}(r=0.503)$, AN $(r=0.478)$ and $\mathrm{AK}(r=0.452)$ were the main correlates of axis 2 (Table 4 ). Plots on the negative part of axis 1 comprise samples of Group 1, distinct for its low SM and soil fertility. Plots spreading on the most positive axis 1 belong to Group 3, and were typically high in SM content. Plots distributed in the middle part of axis 1 were transition types belonging to Group 2. Along axis 1, plots were associated positively with SM and negatively with soil $\mathrm{pH}$.

In herbs, factors that were highly correlated with axis 1 included SM (Spearman $r=0.733$ ), (TK, Spearman $r=0.451$ ) and $\mathrm{pH}$ (Spearman $r=-0.723$ ) (Table 4), while the main correlations to axis 2 were (AN, Spearman $r=0.484$ ) and AK (Spearman $r=0.497$ ). At the top left of the ordination diagram, plots collected along $\mathrm{T}_{3}$ and $\mathrm{T}_{5}$ belong to Group C. At the bottom right of the ordination diagram, Group A occurred with high-SM content. Plots in the middle part of axes 1 and 2 were widely spread out and mostly overlapped. 


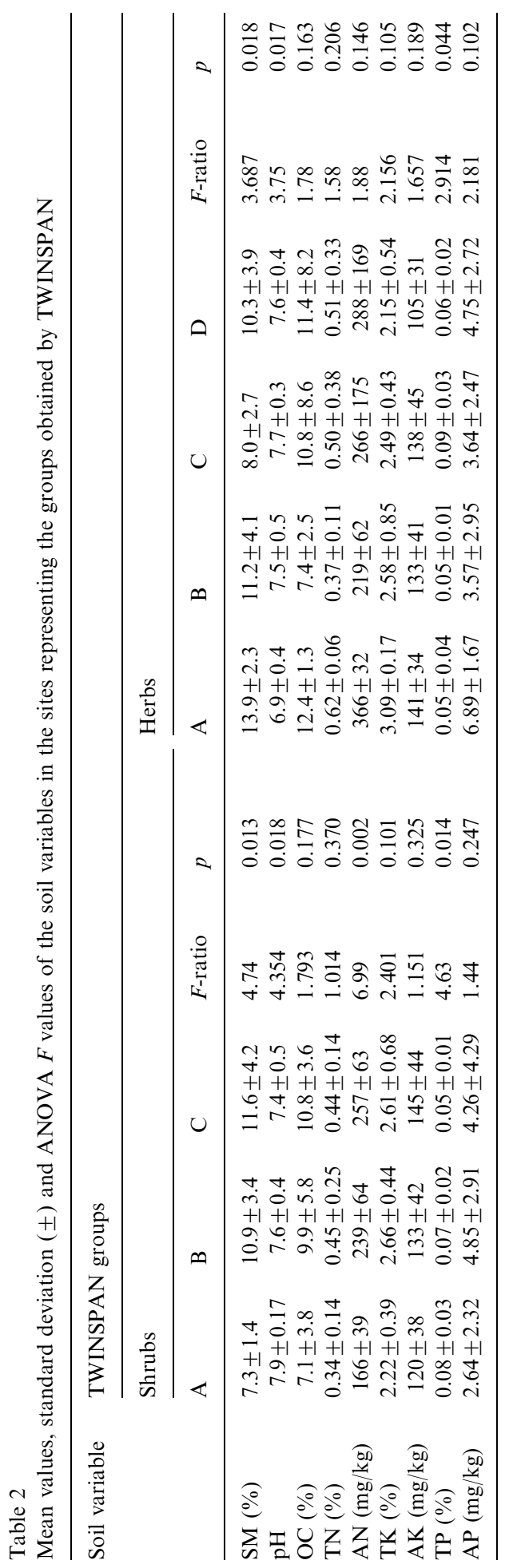


Table 3

Comparison of the results with DCA and DCCA

\begin{tabular}{|c|c|c|c|c|}
\hline & \multicolumn{2}{|l|}{ Shrubs } & \multicolumn{2}{|l|}{ Herbs } \\
\hline & Axis 1 & Axis 2 & Axis 1 & Axis 2 \\
\hline \multicolumn{5}{|l|}{$D C C A$} \\
\hline Eigenvalues & 0.792 & 0.399 & 0.780 & 0.233 \\
\hline Variance explained $(\%)^{\mathrm{a}}$ & 12.4 & 18.7 & 12.2 & 15.9 \\
\hline \multicolumn{5}{|l|}{$D C A$} \\
\hline Eigenvalues & 0.831 & 0.461 & 0.879 & 0.424 \\
\hline
\end{tabular}

${ }^{\mathrm{a}}$ Cumulative variance in species data.

\subsubsection{Species ordination}

The results obtained from species ordination were summarized with respect to the most important edaphic factors as identified by DCCA (Fig. 4). In shrub layer, species with negative scores on axis 1 included Indigofera bungeana and Sophora viciifolia. Those two species were dominants on transect $\mathrm{T}_{3}$, where the SM content was especially low. In the middle part of axes 1 and 2, neutral species were found, including Jasminum humile, Cynoglossum amabile and Caryopteris terniflora. Species with high positive scores in axes 1 and 2 included Spiraea longigemmis, Wikstroemia modesta, Desmodium podocarpum and Cotinus coggygria var. glaucophylla. Those species were positively associated with SM and soil fertility, and were mainly found along $\mathrm{T}_{1}$ and $\mathrm{T}_{6}$.

For herbs, species with high positive scores on DCCA axes 1 and 2 included Pteris inaequalis, Carex lanceolata, Senecio setchuensis and Artemisia sylvatica. They are associated positively with SM content and soil fertility factors. These species were mainly found along $\mathrm{T}_{1}$ and $\mathrm{T}_{6}$. Species with negative scores on DCCA axis 1 included typical xerophil species such as Tragus berteronianus, Ajania breviloba and Sedum wenchuanense, and were correlated positively with soil $\mathrm{pH}$ and negatively with SM. In the middle of axis 1, most species were annuals, such as Rubia ovatifolia, Eulalia quadrinervis and Onosma farrerii. Species with the highest scores on axis 2 appeared to be indicative of high SM content and high fertility, such as Thalictrum robustum, Capillipedium parviflorum and Artemisia sylvatica. The majority of the species located in the middle of axis 2 occurred mainly on semi-south-facing and -north-facing slope, including Artemisia sieversiana, Polygala japonica, Leontopodium leontopodioides and Bupleurum tenue. Species with the lowest scores on axis 2 also had the lowest scores on axis 1.

These results suggest that SM and fertility criteria can be used to classify groups both in the shrub and in the herb stratal layers in an arid valley. Major soil fertility criteria were $\mathrm{AK}, \mathrm{AN}, \mathrm{OC}$, and soil $\mathrm{pH}$. Although the clustering of DCCA ordination was not as definitive as that in TWINSPAN classification, the two techniques provided complimentary results.

\subsection{Partition of the ecological variation}

According to Borcard's method (1992), the whole variation of a species matrix can be partitioned as (a) nonspatial environmental variation, (b) spatially structured environmental variation, (c) spatial species variation that is not shared by the environmental 

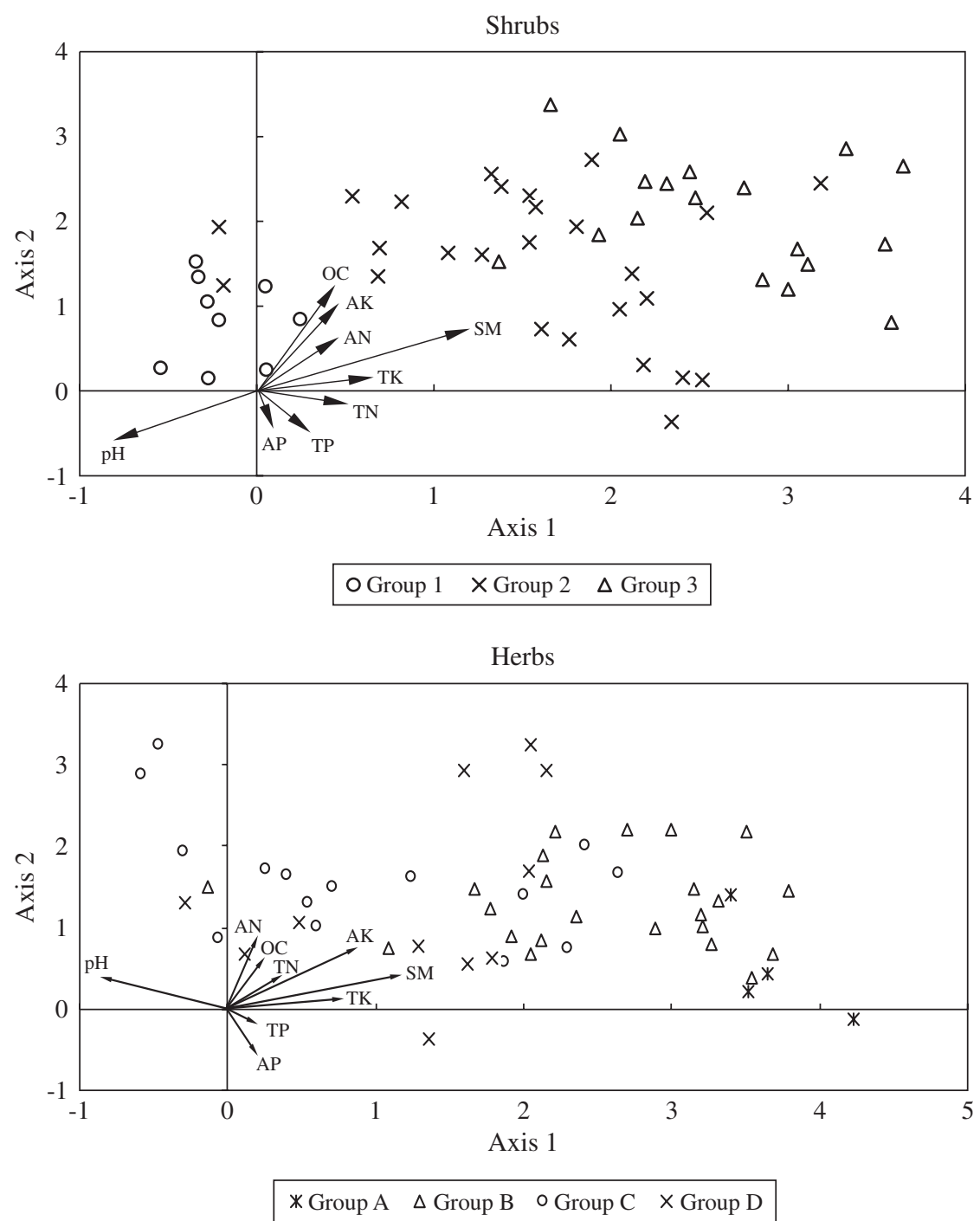

Fig. 3. DCCA plots ordination of the shrubs and herbs with the group types derived from TWINSPAN superimposed. The vectors represent environmental variables. The length of the vector is proportional to its importance and the angle between two vectors reflects the degree of correlation between variables. The angle between a vector and each axis is related to its correlation with the axis.

variables, and (d) unexplained variation and stochastic fluctuations. Applying this method in our study, the relative importance of various processes that control variation of shrubs and herbs can be illustrated (Fig. 5). The overall amount of explained variation was $47.62 \%$ in shrubs and $26.57 \%$ in herbs (parts $a+b+c$ in Fig. 5). In shrubs, soil variables explained $36.93 \%$ (parts a + b in Fig. 5) of the variation in the species matrix, where $8.91 \%$ (part b in Fig. 5) was predicted by the geographical coordinates of the plots. For herbs, soil variables explained $21.47 \%$ (parts $\mathrm{a}+\mathrm{b}$ in Fig. 5) and geographical variables explained 
Table 4

Intra-set correlations of soil variables with the first two axes of DCCA

\begin{tabular}{|c|c|c|c|c|}
\hline \multirow[t]{2}{*}{ Soil factor } & \multicolumn{2}{|l|}{ Shrubs } & \multicolumn{2}{|l|}{ Herbs } \\
\hline & Axis 1 & Axis 2 & Axis 1 & Axis 2 \\
\hline Soil moisture content & $0.657 * *$ & 0.130 & $0.733^{* *}$ & 0.201 \\
\hline $\mathrm{pH}$ & $-0.615^{* *}$ & $-0.373^{*}$ & $-0.723^{* *}$ & 0.193 \\
\hline Soil organic matter & $0.382 *$ & $0.503^{* *}$ & 0.235 & $0.358^{*}$ \\
\hline Total nitrogen & $0.377^{*}$ & -0.104 & $0.404^{*}$ & 0.117 \\
\hline Available nitrogen & $0.371^{*}$ & $0.478 * *$ & 0.278 & $0.484 * *$ \\
\hline Total potassium & $0.349^{*}$ & 0.066 & $0.451 * *$ & 0.041 \\
\hline Available potassium & 0.230 & $0.452 * *$ & $0.359 *$ & $0.497 * *$ \\
\hline Total phosphorus & 0.247 & $-0.359 *$ & 0.067 & -0.025 \\
\hline Available phosphorus & 0.061 & -0.184 & 0.176 & $-0.397 *$ \\
\hline
\end{tabular}

$* * p<0.001 ; * p<0.01$.

$0.83 \%$ (part b in Fig. 5), respectively. The amount of unexplained species variation was $52.39 \%$ in shrubs, and $73.43 \%$ (part d in Fig. 5), rather high, in herbs.

\section{Discussion}

Our data support the view that shrubs and herbs respond to the environment differently. The difference can be briefly explained by the different life-form spectrums of shrubs and herbs, and it is not surprising that shrubs and herbs may have different strategies for resource use and different competitive and physiological abilities. Still, we found that the observed differences between shrubs and herbs can be explained by three ecological interpretations.

Firstly, shrubs and herbs responded to spatial features differently. As TWINSPAN classification showed in our study, shrubs were grouped according to sample sites (Fig. 2), and their distribution obviously represented different characteristics of the three types of environments. However, this accordance did not exist in herbs. Thus, the distribution of shrubs was mainly influenced by large-scale environmental variation, e.g. elevation, while herb distribution was more likely determined by local environmental variation, such as micro-topography. The results were consistent with previous studies that showed herbaceous species may be relatively more influenced by local factors, such as soil conditions, disturbance, and degrees of canopy cover, rather than macro-scale factors (Vetaas, 1997; Bhattarai and Vetaas, 2003).

Secondly, shrubs and herbs had different competitive abilities even within the same community. Herbs were often less exposed to some components of the environment (e.g. light) when sheltered by shrubs in a shrub-dominant community. It is well known that shade has a significant influence on herbaceous growth, and woody plants may influence the environments under their canopies, changing SM and nutrients, light availability, and temperature (Belsky, 1994; Mordelet and Menaut, 1995; Scholes and Archer, 1997). Some studies have shown that understory sites have higher SM than open grassland sites (Joffre and Rambal, 1993; Scholes and Archer, 1997). Our results supported this view and implied that even in an arid community like the Tibetan Plateau, environmental resource use by 

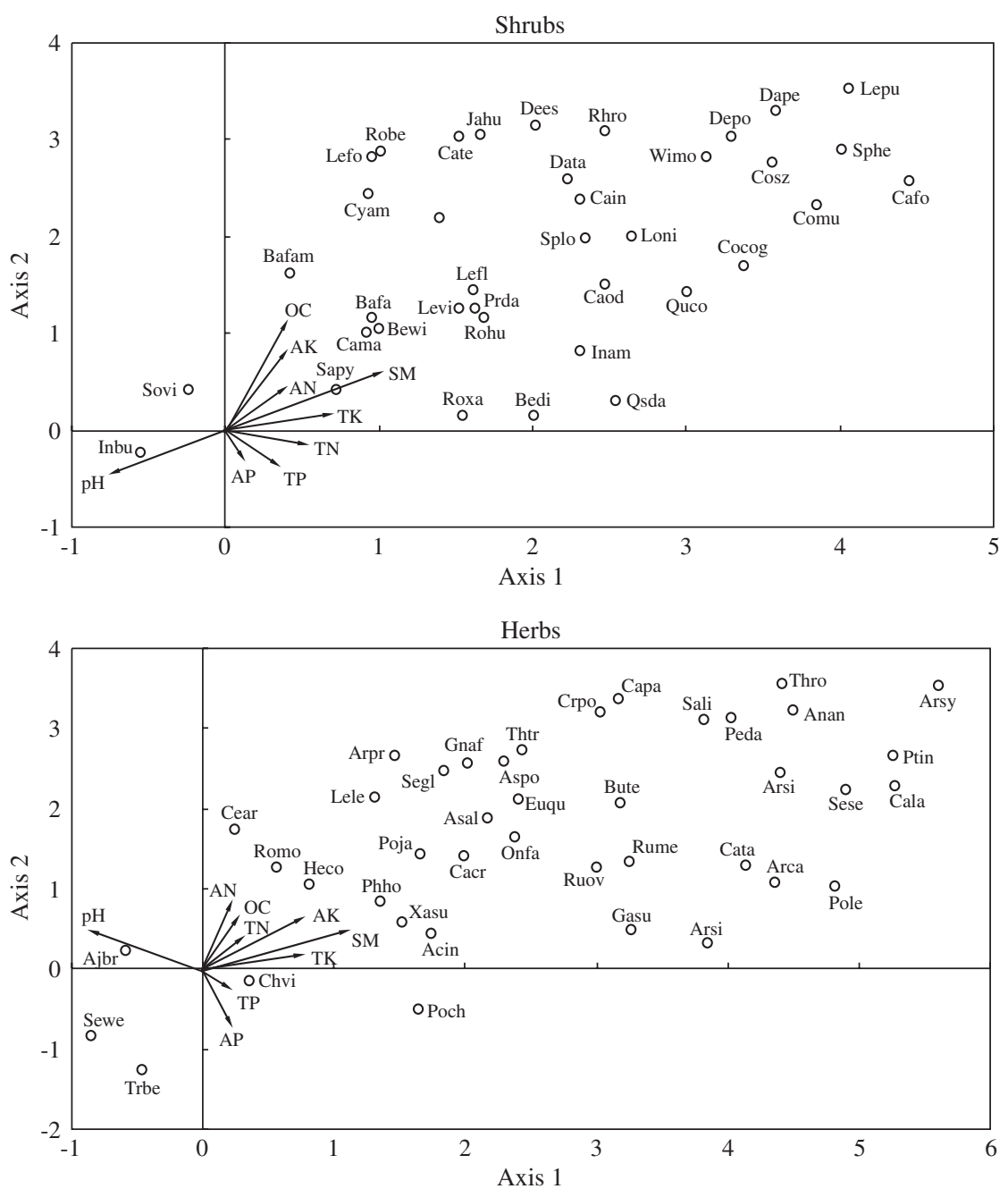

Fig. 4. DCCA species ordination of the shrubs and herbs. The vectors represent environmental variables. The length of the vector is proportional to its importance and the angle between two vectors reflects the degree of correlation between variables. The angle between a vector and each axis is related to its correlation with the axis. For species abbreviations see Appendix A.

herbs is largely altered, if not completely controlled, by shrubs, the more competitive functional group.

Thirdly, shrubs had a more stable and tight relationship with soil factors compared to herbs. Following Walter's (1971) two-layer hypothesis for water relations and coexistence of plants in arid and semi-arid environments, relevant studies have shown that plants differ in their use of water resources in water-limited environments (Montaña et al., 1995; Golluscio et al., 1998; Yoder and Nowak, 1999), especially in semi-arid regions with annual rainfall $>300 \mathrm{~mm}$, where deep infiltration occurs more commonly (Reynolds et al., 2000). Schwinning et al. (2005b) showed that the water status of the deepest-rooted shrub was least negatively affected by severe drought conditions, and often experience less water 


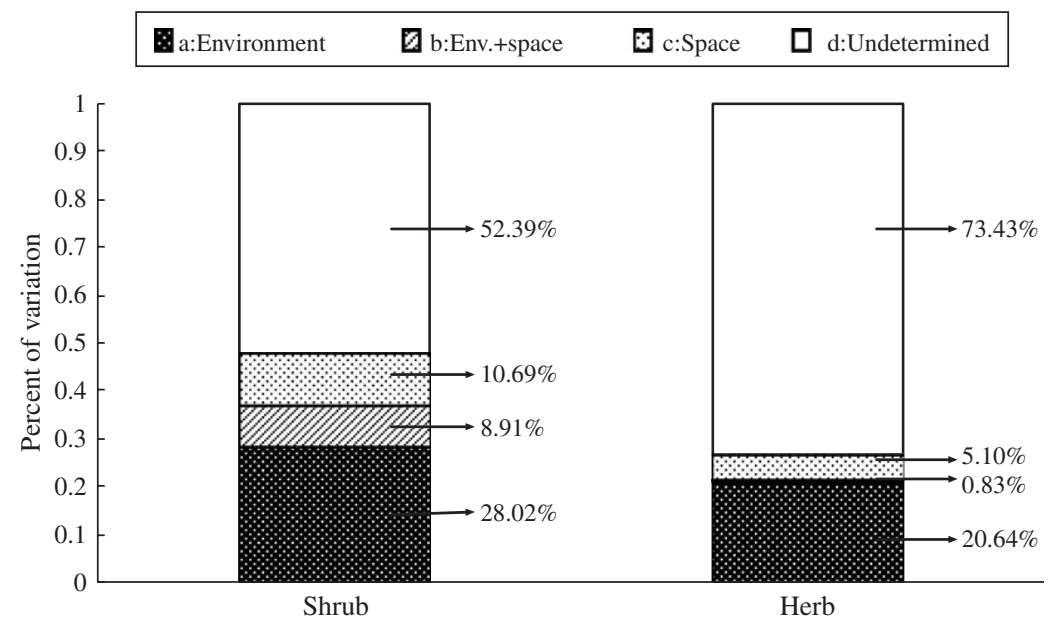

Fig. 5. Variation partitioning of the species data in shrubs and herbs.

stress during dry inter-pulse periods than shallow-rooted plants, because they had the ability to draw on deep-water reserves left over from previous rainy seasons (Davis and Mooney, 1985; Schwinning et al., 2002; Ogle and Reynolds, 2004). Our result supported this concept. Normally, shrubs have more extensive root systems than herbs in our study area, and are capable of utilizing water stored in different soil profiles, hence it is strongly determined by the environment. On the contrary, shallow-rooting herbs can only utilize the transient water stored in the upper soil synchronic with precipitation pulses, hence they are more sensitive to the environment and respond faster than woody plants (Knoop and Walker, 1985).

Our study has some limitations. Above all, it is clear that edaphic variables were not the only factors associated with the distribution of species in the study area, although they were usually the most important (Monier and Wafaa, 2003; Jafari et al., 2004). In addition, our study only examined one scale. Using different scales, factors-dominating species composition could be different, for the resource variation is scale-dependent (Levins, 1992; Anderson et al., 2004), which may result in different species-environment relationships between stratal layers. Previous work has shown that at large scales, species abundance patterns have been attributed to habitat heterogeneity or environmental gradients, which fail to account for small-scale species interactions and the acquisition of resources (Whittaker and Niering, 1975; Shmida and Wilson, 1985; Currie, 1991), thus the different species-environment interactions between strata would be masked. In addition, the scales that affect species distribution may be not the same between different layers too. Lastly, the habitat investigated in our study was relatively simple, in which species capable of surviving have to withstand harsh environmental conditions. Thus, some ecological processes may not be the same as in another habitat.

\section{Conclusions}

Validating hypotheses that test whether shrubs and herbs respond differently to the environments can be critical for understanding ecological processes. The approach taken in 
our study was different from previous studies in that it used quantitative analysis techniques to determine whether different layer species respond differently to the environment. By quantitative analysis, our initial assumption was supported that shrubs and herbs had specific relations with environmental variables (Table 4), and the explained ecological variation of herbs was lower than that of shrubs (Fig. 5). We suggest that the attempts to understand the plant community can only be successful if the above assumption is studied, and investigators must be aware of the strata-related limitations of any study. This article presents the beginning of a methodology to do so, and it can be a starting point for further research.

\section{Acknowledgments}

We thank Guohua Liu, Yihe Lü, Shiliang Liu, Rongjin Yang, Yilong Huang, Zhilin Huang, Yuxin Zhang, Yongxiang Kang, Jianyun Zhou, Chunhua Xie, and Jianan Wu for their valuable devotion in the field investigation. This study was supported by The National Natural Science Foundation of China (No. 40571005) to B. Fu, The Development Plan of the State Key Fundamental Research of China (973) to K. Ma (No. 2003CCB00400), and the Innovation Group Program of National Natural Science Foundation of China (No. 40321101) to B. Fu.

\section{Appendix A}

For the name and abbreviations of the spcies displayed, see Table A.1.

Table A.1

Names and abbreviations of the species displayed in Fig. 4

\begin{tabular}{ll}
\hline Species & Abbreviations \\
\hline Achnatherum inaequiglume Keng. & Acin \\
Ajania breviloba L. & Ajbr \\
Artemisia annua L. & Aran \\
Artermisia capillaris Thunb. & Arca \\
Artemisia sieversiana Willd. & Arsi \\
Artemisia sylvatica Maxim. & Arsy \\
Arthraxon prionodes (Steud.) Dandy & Arpr \\
Aster albescens (DC.) Hand.-Mazz. & Asal \\
Aster poliothamnus Diels. & Aspo \\
Bauhinia faberi Oliver. & Bafa \\
Bauhinia faberi var.microphylla Oliver. & Bafam \\
Berberis diaphana Maxim. & Bedi \\
Berberis wilsonae Hemsl. & Bewi \\
Bupleurum tenue Buch.-Ham. Ex D. Don & Bute \\
Campylotropis macrocarpa (Bge.) Rehd. & Cama \\
Capillipedium parviflorum (R. Br.) Stapf & Capa \\
Cardamine tangutorum O.E. Schulz. & Cata \\
Carex crebra V. Krecz & Cacr \\
Carex lanceolata Boott & Cala \\
Caryopteris forrestii Diels. & Cafo
\end{tabular}


Table A.1 (continued)

Species

Caryopteris incana Miq.

Caryopteris odorata (D. Don) B.L.R.L. Robinson

Caryopteris terniflora Maxim.

Ceratoides arborescens (Losinsk.) Tsien et C.G. Ma

Chloris virgata $\mathrm{Sw}$.

Cotinus coggygria var. glaucophylla C.Y. Wu

Cotinus szechuanensis A. Penzes

Cotoneaster multiflorus Bge.

Cremanthodium potaninii $\mathrm{C}$. Winkl.

Cynoglossum amabile Stapf et Drumm.

Daphne penicillata Rehd.

Daphne tangutica Maxim.

Desmodium esquirolii Levl.

Desmodium podocarpum DC.

Eulalia quadrinervis (Hack.) Kuntze

Galium sungpanense Cuf.

Gnaphalium affine D. Don

Heteropogon contortus (L.) Beauv. ex Roem. \& Schult.

Indigofera amblyantha Craib.

Indigofera bungeana Steud.

Jasminum humile Linn.

Leontopodium leontopodioides (Willd.) Beauv.

Leptodermis purdomii Hutch.

Lespedeza floribunda Bunge

Lespedeza formosa (Vog.) Koehne

Lespedeza virgata (Thunb.) DC.

Lonicera nispida E.Wilson

Onosma farrerii Johnst.

Pedicularis davidii Franch.

Phemeda hookeri (Griseb.) A. Camus

Poa chalarantha L.

Polygala japonica Houtt.

Potentilla leuconota D. Don

Prunus davidiana (Carr.) Franch.

Pteris inaequalis Bak.

Qstryopsis davidianti Stapf

Quercus cocciferoides Hand.-Mazz.

Rhamnus rosthornii Pritz.

Rorippa montana (Wall.) Small.

Rosa bella Rehd. et Wils.

Rosa hugonis Hemsl.

Rosa xanthina Lindl.

Rubia membranacea Diels

Rubia ovatifolia Z.Y. Zhang

Sageretia pycnophylla Schneid.

Saussurea licentiana Hand.-Mat.

Sedum wenchuanense $\mathrm{Fu}$

Senecio setchuensis Franch.

Setaria glauca (L.) Beauv.

Sophora viciifolia Hance

Spiraea henryi Hemsl.

Spiraea longigemmis Maxim.
Abbreviations

Cain

Caod

Cate

Cear

Chvi

Cocog

$\operatorname{Cos} z$

Comu

Crop

Cyam

Dape

Data

Dees

Depo

Euqu

Gasu

Gnaf

Heco

Inam

Inbu

Jahu

Lele

Lери

Lefl

Lefo

Levi

Loni

Onfa

Peda

Phho

Poch

Poja

Pole

Prda

Ptin

Osda

Quco

Rhro

Room

Robe

Rohu

Roxa

Rume

Ruov

Sapy

Sali

Sewe

Sese

Segl

Sovi

Sphe

Splo 
Table A.1 (continued)

\begin{tabular}{ll}
\hline Species & Abbreviations \\
\hline Thalictrum robustum Maxim. & Thro \\
Thalictrum thunbergii Dc. & Thth \\
Themeda triandra Forsk. & Thtr \\
Tragus berteronianus Schult. & Trbe \\
Wikstroemia modesta (Rehd.) Domke & Wimo \\
Xanthopappus subacaulis C. Winkl. & Xasu \\
Zanthoxylum simulans Hance & Zasi \\
\hline
\end{tabular}

\section{References}

Abbadi, G.A., El-Sheikh, M.A., 2002. Vegetation analysis of Failaka Island (Kuwait). Journal of Arid Environments 50, 153-165.

Anderson, T.M., McNaughton, S.J., Ritchie, M.E., 2004. Scale-dependent relationships between the spatial distribution of a limiting resource and plant species diversity in an African grassland ecosystem. Oecologia 139, 277-287.

Belsky, A.J., 1994. Influences of trees on savanna productivity: tests of shade, nutrients, and tree-grass competition. Ecology 75, 922-932.

Bhattarai, K.R., Vetaas, O.R., 2003. Variation in plant species richness of different life forms along a subtropical elevation gradient in the Himalayas, east Nepal. Global Ecology and Biogeography 12, 327-340.

Borcard, D., Legendre, P., Drapeau, P., 1992. Partialling out the spatial component of ecological variation. Ecology 73, 1045-1055.

Currie, D.J., 1991. Energy and large-scale patterns of animal and plant species richness. American Nauralist 137, $27-49$.

Dargie, T.C.D., El-Demerdash, M.A., 1991. A quantitative study of vegetation-environment relationships in two Egyptian deserts. Journal of Vegetation Science 2, 3-10.

Davis, S.D., Mooney, H.A., 1985. Comparative water relations of adjacent California shrub and grassland communities. Oecologia 66, 522-529.

Editorial Board of Sichuan Vegetation, 1980. Sichuan Vegetation. People's Publishing House of Sichuan, Chengdu (in Chinese).

Editorial Committee, 1996. Soil Physical and Chemical Analysis and Description of Soil Profiles. Standards Press of China, Beijing (in Chinese).

Ehleringer, J.R., Phillips, S.L., Schuster, W.S.F., Sandquist, D.R., 1991. Differential utilization of summer rains by desert plants. Oecologia 88, 430-434.

El-Ghareeb, R., Shabana, M.A., 1990. Vegetation-environment relationships in the bed of Wadi El-Sheikh of southern Sinai. Vegetatio 90, 145-157.

Fao-Unesco, 1988. Soil Map of the World, revised legend. World Soil Resources Report 60. FAO, Rome.

Gauch, H.G., Whittaker, R.H., 1981. Hierarchical classification of community data. Journal of Ecology 69, 537-557.

Golluscio, R.A., Sala, O.E., Lauenroth, W.K., 1998. Differential use of large summer rainfall events by shrubs and grasses: a manipulative experiment in the Patagonian steppe. Oecologia 115, 17-25.

He, Y.C., Zhong, X.H., Zhang, N., Li, L.H., 1993. Basic laws of water and soil loss and the construction of protection forests in the Upper Reaches of the Changjiang River. In: Yang, Y.P. (Ed.), Researches on the Chuanjiang Protection Forests in the Upper Reaches of the Changjiang River. Science Press, Beijing (in Chinese).

Hill, M.O., 1979. TWINSPAN: A Fortran Program for Arranging Multivariate Data in an Ordered Two-Way Table by Classification of the Individuals and Attributes. Cornell University, New York.

Hobbie, S., 1992. Effects of plant species on nutrient cycling. Trends in Ecology and Evolution 7, 336-339.

Holzapfel, C., Mahall, B.E., 1999. Bidirectional facilitation and interference between shrubs and annuals in the Mojave desert. Ecology 80, 1747-1761. 
Jafari, M., Zare Chahoukib, M.A., Tavilib, A., Azarnivandb, H., Zahedi Amirib, Gh., 2004. Effective environmental factors in the distribution of vegetation types in Poshtkouh rangelands of Yazd Province (Iran). Journal of Arid Environments 56, 627-641.

Joffre, R., Rambal, S., 1993. How tree cover influences the water balance of Mediterranean rangelands. Ecology $74,570-582$.

Johnson, D.H., 1995. Statistical sirens: the allure of nonparametrics. Ecology 76, 1998-2000.

Kent, M., Coker, P., 1992. Vegetation Description and Analysis-A Practical Approach. Wiley, Chichester.

Knoop, W.T., Walker, B.H., 1985. Interactions of woody and herbaceous vegetation in a southern African savanna. Journal of Ecology 73, 235-253.

Lei, X.Z., Huang, L.L., 1993. A study of features of soil erosion in part of the areas along the upper reaches of the Changjiang River. In: Yang, Y.P. (Ed.), Researches on the Chuanjiang Protection Forests in the Upper Reaches of the Changjiang River. Science Press, Beijing (in Chinese).

Levins, S.A., 1992. The problem of pattern and scale in ecology. Ecology 73, 1943-1967.

Lin, G., Phillips, S.L., Ehleringer, J.R., 1996. Monsoonal precipitation responses of shrubs in a cold desert community on the Colorado Plateau. Oecologia 106, 8-17.

Ma, K.M., Fu, B.J., Liu, S.L., Guan, W.B., Liu, G.H., Lü, Y.H., Anand, M., 2004. Multiple-scale soil moisture distribution and its implications for ecosystem restoration in an arid river valley, China. Land Degradation and Development 15, 75-85.

Maestre, F.T., Bautista, S., Cortina, J., 2003. Positive, negative, and net effects in grass-shrub interactions in Mediterranean semiarid grasslands. Ecology 84, 3186-3197.

McDonald, D.J., Cowling, R.M., Boucher, C., 1996. Vegetation-environment relationships on a species-rich coastal mountain range in the fynbos biome (South Africa). Vegetatio 123, 165-182.

Monier, M.A.E.-G., Wafaa, M.A., 2003. Soil-vegetation relationships in a coastal desert plain of southern Sinai, Egypt. Journal of Arid Environments 55, 607-628.

Montaña, C., Cavagnaro, B., Briones, O., 1995. Soil water by co-existing shrubs and grasses in the Southern Chihuahuan Desert, Mexico. Journal of Arid Environments 31, 1-13.

Mordelet, P., Menaut, J.C., 1995. Influence of trees on above-ground production dynamics of grasses in a humid savanna. Journal of Vegetation Science 6, 223-228.

Nelson, D.W., Sommers, L.E., 1975. A rapid and accurate method for estimating organic carbon in soil. Proceedings of the Indiana Academy of Science 84, 456-462.

Ogle, K., Reynolds, J.F., 2004. Plant responses to precipitation in desert ecosystems: integrating functional types, pulses, thresholds, and delays. Oecologia 141, 282-294.

Oksanen, J., Minchin, P.R., 1997. Instability of ordination results under changes in input data order: explanations and remedies. Journal of Vegetation Science 8, 447-454.

Palmer, M., 1993. Putting things in even better order: the advantages of canonical correspondence analysis. Ecology 74, 2215-2230.

Parkinson, J.A., Allen, S.E., 1975. A wet oxidation procedure suitable for determination for nitrogen and mineral nutrients in biological material. Communications in Soil Science and Plant Analysis 6, 1-11.

Pugnaire, F.I., Lazaro, R., 2000. Seed bank and understorey species composition in a semi-arid environment: the effect of shrub age and rainfall. Annals of Botany 86, 807-813.

Pugnaire, F.I., Haase, P., Puigdefabregas, J., 1996. Facilitation between higher plant species in a semiarid environment. Ecology 77, 1420-1426.

Reynolds, J.F., Kemp, P.R., Tenhunen, J.D., 2000. Effects of long-term rainfall variability on evapotranspiration and soil water distribution in the Chihuahuan Desert: a modeling analysis. Plant Ecology 150, 145-159.

Schenk, H.J., Holzapfel, C., Hamilton, J.G., Mahall, B.E., 2003. Spatial ecology of a small desert shrub on adjacent geological substrates. Journal of Ecology 91, 383-395.

Scholes, R.J., Archer, S.R., 1997. Tree-grass interactions in savannas. Annual Review of Ecology and Systematics $28,517-544$.

Schwinning, S., Davis, K., Richardson, L., Ehleringer, J.R., 2002. Deuterium enriched irrigation indicates different forms of rain use in shrub/grass species of the Colorado Plateau. Oecologia 130, 345-355.

Schwinning, S., Starr, B.I., Ehleringer, J.R., 2005a. Summer and winter drought in a cold desert ecosystem (Colorado Plateau), Part I: Effects on soil water and plant water uptake. Journal of Arid Environments 60, $547-566$.

Schwinning, S., Starr, B.I., Ehleringer, J.R., 2005b. Summer and winter drought in a cold desert ecosystem (Colorado Plateau), Part II: Effects on plant carbon assimilation and growth. Journal of Arid Environments $61,61-78$. 
Shmida, A., Wilson, M.V., 1985. Biological determinants of species diversity. Journal of Biogeography 12, 1-20. ter Braak, C.J.F., 1986. Canonical correspondence analysis: a new eigenvector technique for multivariate direct gradient analysis. Ecology 67, 1167-1179.

ter Braak, C.J.F., 1987. The analysis of vegetation-environment relationships by canonical correspondence analysis. Vegetatio 69, 69-77.

ter Braak, C.J.F., Prentice, I.C., 1988. A theory of gradient analysis. Advances in Ecological Research 18, 271-317.

ter Braak, C.J.F., Smilauer, P., 1998. CANOCO Reference Manual and User's Guide to Canoco for Windows: Software for Canonical Community Ordination (Version 4). Microcomputer Power, Ithaca, New York.

Turner, J., Kelly, J., 1981. Relationships between soil nutrients and vegetation in a north coast forest. Australian Forest Research 11, 201-208.

Vetaas, O.R., 1997. The effect of canopy disturbance on species richness in a central Himalayan oak forest, Nepal. Plant Ecology 132, 29-38.

Vogiatzakis, I.N., Griffiths, G.H., Mannion, A.M., 2003. Environmental factors and vegetation composition, Lefka Ori massif, Crete, S. Aegean. Global Ecology and Biogeography 12, 131-146.

Walter, H., 1971. Natural Savannahs as a transition to the Arid Zone. In: Ecology of Tropical and Subtropical Vegetation. Oliver \& Boyd, Edinburgh.

Wang, G.G., 1995. White spruce site index in relation to soil, understory vegetation, and foliar nutrients. Canadian Journal of Forest Research 25, 29-38.

Whittaker, R.H., Niering, W.A., 1975. Vegetation of the Santa Catalina Mountains, Arizona. V. Biomass, production and diversity along an elevational gradient. Ecology 56, 771-790.

Wilson, J.W., Agnew, O.D.Q., 1992. Positive-feedback switches in plant communities. Advances in Ecological Research 20, 265-336.

Yoder, C.K., Nowak, R.S., 1999. Soil moisture extraction by evergreen and drought-deciduous shrubs in the Mojave Desert during wet and dry years. Journal of Arid Environments 42, 81-96.

Zhang, R.Z., 1992. The Arid Valleys of the Hengduan Mountains Region. Science Press, Beijing (in Chinese). 